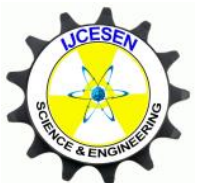

Copyright (C) IJCESEN
International Journal of Computational and

Experimental Science and $\boldsymbol{E N g i n e e r i n g}$

(IJCESEN)

Vol. 5-No.3 (2019) pp. 112-118

http://dergipark.gov.tr/ijcesen

Research Article

\title{
The Effect of Exhaust Temperature on Urea-Water Decomposition in Marine SCR Systems
}

\author{
Kubilay BAYRAMOĞLU*, Güner ÖZMEN, A. Güldem CERİT \\ Dokuz Eylul University, Maritime Faculty, Marine Engineering Department, 35390, Izmir-Turkey \\ * Corresponding Author: kubilay.bayramoglu@ deu.edu.tr \\ ORCID: 0000-0002-5838-6132
}

\section{Article Info:}

DOI:10.22399/ijcesen.578973

Received : 17 June 2019

Accepted : 09 August 2019

\section{$\underline{\text { Keywords }}$}

Marine SCR

Simulation

$\mathrm{NO}_{\mathrm{x}}$ Reduction

Urea decomposition

\begin{abstract}
:
Reduction of nitrogen oxide $\left(\mathrm{NO}_{\mathrm{x}}\right)$ emissions from ships due to environmental pollution and greenhouse gas impact has been made obligatory by regulations introduced by the International Maritime Organization (IMO). Basically, $\mathrm{NO}_{\mathrm{x}}$ emission control mechanisms are divided into primary methods and aftertreatment methods. After-treatment methods focus on reducing $\mathrm{NO}_{\mathrm{x}}$ emissions from the exhaust gas by various methods. In this study, the efficiency of the urea transformation for different exhaust temperature values for a modelled Selective Catalytic Reduction (SCR) system has been investigated numerically. As a result of numerical model, isocyanic acid, temperature, urea and ammonia values have been determined for Urea-Water Solutions (UWS) process values. The study has been calculated by the computational fluid dynamics (CFD). The numerical results obtained were confirmed by experimental studies from the literature.
\end{abstract}

\section{Introduction}

$\mathrm{NO}_{\mathrm{x}}$ harmful gases which cause environmental pollution are formed during the combustion process in diesel engines. The amount of $\mathrm{NO}_{\mathrm{x}}$ emissions from shipping on annual has been reported to be 10 million tons in the world [1]. In order to prevent $\mathrm{NO}_{\mathrm{x}}$ emissions from ships, mandatory regulations have been introduced by IMO. $\mathrm{NO}_{\mathrm{x}}$ emission limits for diesel engines has been determined depending on engine speed by Tier III as of 1 January 2016 [2]. Figure 1 below shows the restriction imposed by IMO for the reduction of NOx emissions from ships depend on the engine cycles over the years [3]. Different technologies have been developed to reduce $\mathrm{NO}_{\mathrm{x}}$ pollution from ships. The urea-SCR system is one of the most useful methods to reduce $\mathrm{NO}_{\mathrm{x}}$ emissions in the exhaust gas. However, reducing the amount of $\mathrm{NO}_{\mathrm{x}}$ in the SCR system depends on the formation of enough ammonia in the catalyst. When the urea-water solution is injected into the exhaust gas, enough space and time is needed until ammonia is formed. SCR

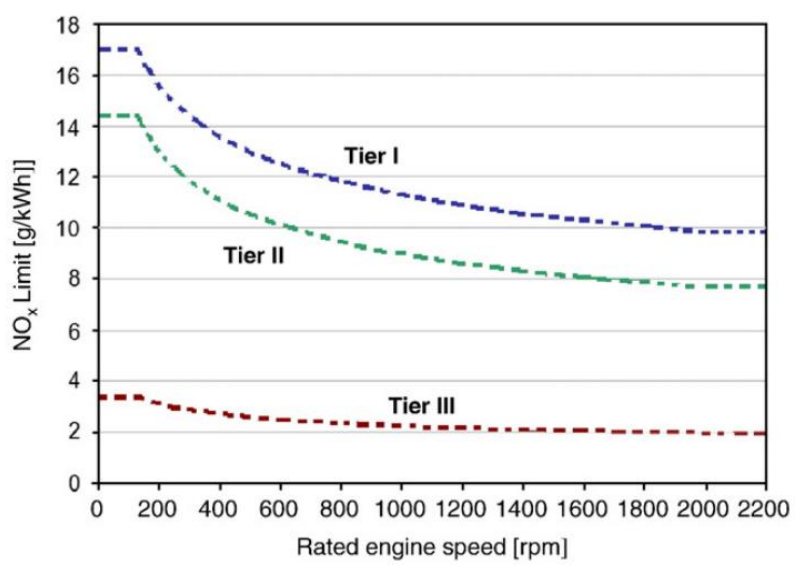

Figure 1. $N O_{x}$ emission limits

performance has been influenced by exhaust gas temperature and The static mixer which allow ammonia to be distributed uniformly before entrance of catalyst [4]. Figure 2 shows the SCR system installed in the diesel engine exhaust line. The reduction behaviour of $\mathrm{NO}_{\mathrm{x}}$ in SCR systems starts with UWS spray. following injection, evaporation of urea-water solution, thermolysis of 

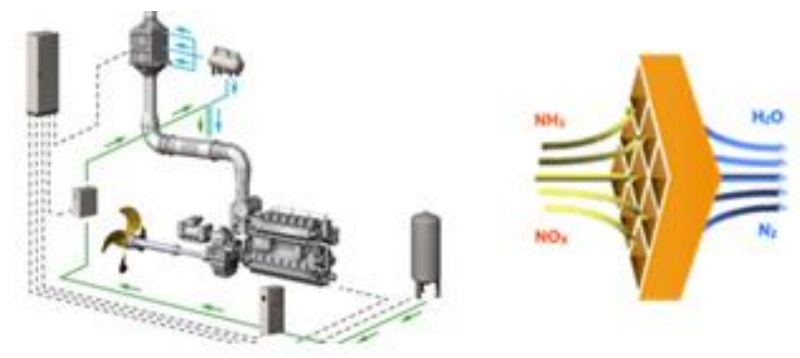

Figure 2. Marine SCR systems

urea, hydrolysis of Isocyanic acid (HNCO) and acid and reduction of $\mathrm{NO}_{\mathrm{x}}$ in the catalyst takes place [5]. Various studies have been done in the literature for evaporation and decomposition processes in SCRurea systems. Um et al. [6] have examined numerically various design parameters such as chamber diameter, inlet and outlet shape of chamber, and urea injection point.

Capetillo and Ibarra [7] have investigated the effect of urea injection rate, spray angle and droplet size on ammonia formation and wall film thickness. Ström et al. [8] have examined the different forces such as drag, buoyancy, lift effect, thermophoresis and history effect that affect the motion of the droplets. Shen et al. [9] has developed a multi-step global kinetic SCR model using real machine data on a 1-D model. The model has been validated by selected engine test data which has wide temperature and space velocity. Kim et al. [10] have designed dimension and geometry for optimum spray characteristics and thermal decomposition. The effect of optimum SCR design on the conversion efficiency of urea solution to ammonia has been investigated experimentally.

Birkhold et al. [11] have investigated urea-water solution and their interaction with exhaust gas flow. In this study, the effect of momentum between gas phase and droplets, evaporation and thermolysis of droplets, heat transfer between walls and particles and spray wall interaction have been investigated. Birkhold et al. [12] have examined the effect of urea on the evaporation of UWS. They have been determined that the vapor pressure decreased due to the increase of the droplet temperature and slow evaporation compared to the pure water. Park et al. [13] have analysed the effect of the mixer on the system by estimating the transport phenomena in the urea-SCR system.

Millo et al. [14] have used commercial silicon carbide $\mathrm{Cu}$ /zeolite SCR-F to control NOx emissions in automotive diesel engines. In the SCR model, both numerical and experimental analyses have been performed for different soot load values.
Nguyen et al. [15] have extended the experimental study of Nguyen et al. [16] On urea-based noncatalyst reduction (SNCR) systems. In this study, hybrid SNCR-SCR system has been investigated experimentally and numerically by using urea solution in pilot SCR reactor.

According to the studies done above, experimental application of SCR systems on ships is very few and insufficient due to the size and cost of equipment [17]. The use of CFD simulations in the investigation and development of thermochemical processes such as the SCR system has become increasingly important [18]. In this study, the effect of different diesel engine exhaust temperature values on urea decomposition has been investigated numerically. The numerical study has been studied with Ansys-Fluent commercial software. In addition, the effect of different temperature values on the parameters such as ammonia formation efficiency, temperature and pressure drop have been investigated.

\section{Methodology}

\subsection{Geometric Model}

The SCR part has examined in the study is composed of $6000 \mathrm{~mm}$ (L) long and $300 \mathrm{~mm}$ (D) diameter pipe as shown in Figure 3. The analysis has been carried out for the hydrolysis, evaporation and thermolysis processes.

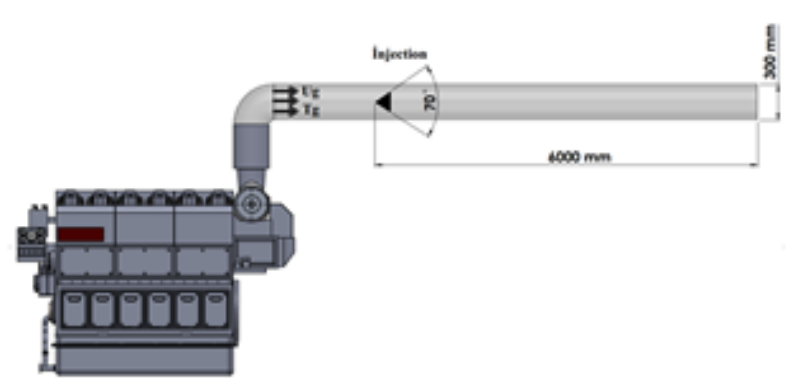

Figure 3. Geometry definition

The exhaust gases entering the SCR system are mixed with the urea solution by increasing and decreasing to the desired temperature with heat exchangers.

\subsection{Governing Equations}

Transport phenomena such as turbulence, chemical reaction, two phase flow and interactions between the gas phase and particles are realized In SCR systems [13]. The physical phenomena that may occur during the urea-water solution injection into the hot exhaust gas in the SCR must be correctly identified. Gas phase solution, spray movement, 
urea-water evaporation, thermal decomposition of urea, chemical reactions and turbulence are required to be defined in the calculations [19].

In the fluid dynamics and heat transfer problems which are examined numerically, the flow of a heat-conducting fluid is governed by the NavierStokes equations which cover the conservation of mass, momentum and energy equations in the system. [19]. In numerical calculations, continuity and momentum equations are expressed as follows [20].

$$
\begin{aligned}
& \frac{89}{8 t}+\frac{8}{8 x}(04)-5
\end{aligned}
$$

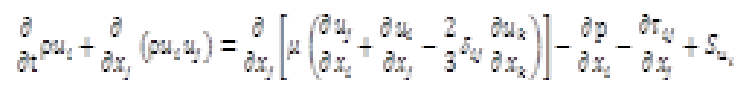

Where, $\rho$ is Favre averaged, $u_{i}$ velocity field, $\mathrm{p}$ averaged pressure, $\tau_{i j}$ stress rate tensor, $S_{p}$ and $S_{u_{i}}$ are source term.

The UWS sprayed into the exhaust gas is converted to water and urea through evaporation in the first step. The reaction may also be in the liquid or molten phase as expressed in the following equation [21].

$$
\mathrm{NH}_{2}-\mathrm{CO}-\mathrm{NH}_{2(\mathrm{~s})} \rightarrow \mathrm{NH}_{2}-\mathrm{CO}-\mathrm{NH}_{2, j)}+\mathrm{xH}_{2} \mathrm{O}_{(\mathrm{g})}
$$

In the process of conversion of urea in exhaust gases, temperature, air flow and pressure are required. Gas or molten urea is converted to isocyanic acid and ammonia at exhaust gas temperatures between 561 and $728 \mathrm{~K}$ [22].

$$
\begin{gathered}
\mathrm{NH}_{2}-\mathrm{CO}-\mathrm{NH}_{2} \rightarrow \mathrm{NH}_{3}+\mathrm{HNCO}_{3} \\
\mathrm{HVCO}+\mathrm{H}_{2} \mathrm{O} \rightarrow \mathrm{NH}_{3}+\mathrm{CO}_{2}
\end{gathered}
$$

Since there is no suitable condition in the phase changes of urea, alternative ways are applied for the decomposition rate in the calculations. Arrhenius expression is used for the decomposition rates of the reactions expressed in the above-defined equations [12].

$$
\frac{d m_{d}}{d t}=-\pi D_{d} A z^{-\pi_{2}}
$$

Where, m mass of reactant $(\mathrm{kg}), \mathrm{t}$ time $(\mathrm{s}), \mathrm{D}_{\mathrm{d}}$

droplet diameter (m), A frequency factor $(\mathrm{kg} / \mathrm{s} . \mathrm{m})$, $\mathrm{E}_{\mathrm{a}}$ activation energy $(\mathrm{J} / \mathrm{mol})$.

\subsection{Numerical Model}

Numerical analysis of thermo -physical phenomena in SCR geometry and CFD results have been obtained by Ansys-Fluent commercial software [23]. The system model and dimensions are designed depending on the machine type and conditions. The computational domain consists of a total of 143k structural meshes, each $20 \mathrm{~mm}$ in size. The SCR computational domain and boundary conditions are described in Figure 4. In this study, inlet boundary condition is defined as inlet of
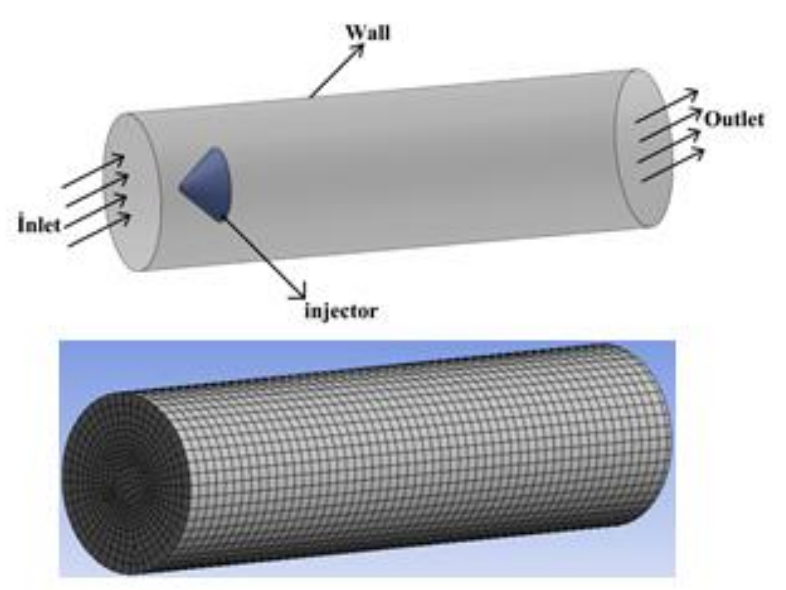

Figure 4. Computational domain

exhaust gas to SCR pipe and outlet boundary condition is defined as catalyst inlet. The study has been analysed as transient and the convergence criterion was $10^{-3}$ for $1 \mathrm{~s}$. Table 1 below refers to the value of the specified boundary conditions. Urea solution used in numerical analysis is $40 \%$ urea $60 \%$ water. The evaporation, hydrolysis and thermolysis of the UWS is provided by the Discrete Phase Model (DPM). The DPM model defines convection, diffusion and

Table 1. Boundary conditions

\begin{tabular}{|c|c|c|}
\hline Boundary Conditions & \multicolumn{2}{|c|}{ Value } \\
\hline Inlet Velocity (m/s) & \multicolumn{2}{|c|}{6} \\
\hline \multirow{3}{*}{ Exhaust Temperature (K) } & Case 1 & 663 \\
\cline { 2 - 3 } & Case 2 & 673 \\
\cline { 2 - 3 } & Case 3 & 683 \\
\hline Wall Temperature (K) & \multicolumn{2}{|c|}{300} \\
\hline Nozzle Diameter (mm) & \multicolumn{2}{|c|}{0.001} \\
\hline Injection Velocity (m/s) & \multicolumn{2}{|c|}{10.6} \\
\hline Injection Temperature (K) & \multicolumn{2}{|c|}{300} \\
\hline Nozzle Cone Angle & 35 \\
(Degree) & \multicolumn{2}{|c|}{} \\
\hline
\end{tabular}

reaction sources for each component species. The DPM model also solves the mixing equations and 
provides recognition and transport of chemical species. In SCR systems, turbulence model is required for pipe flows. $\mathrm{k}-\varepsilon$ turbulence model has been used in the study. The k- $\varepsilon$ turbulence model allows to predict more accurate results for jet flow of the sprayed UWS [24]. There are different evaporation models in the UWS that allow the modelling of water evaporation. The RosinRammler (RM) model is the preferred method of evaporation in the study due to the high transport coefficient for the liquid phases. All the sizes taken in the model were divided a enough discreate. Each disaggregated segment is represented by the average diameter for the trajectory $[12,25]$. The following Table 2 describes the computational submodel boundary conditions.

Table 2. CFD setup boundary conditions

\begin{tabular}{|c|c|}
\hline Boundary Conditions & Value \\
\hline Turbulence Model & k- $\varepsilon$ Standard \\
\hline Droplet Evaporation & Multicomponent model \\
\hline Reaction & $\begin{array}{c}\text { Finite-rate/eddy } \\
\text { dissipation }\end{array}$ \\
\hline Urea Injection & $\begin{array}{c}\text { Discrete particle tracking } \\
\text { model }\end{array}$ \\
\hline Diameter Distribution & Rosin-Rammler \\
\hline
\end{tabular}

\subsection{Model Validation}

The most important disadvantage of numerical studies is that their accuracy depends on various parameters. The results of numerical analysis can be confirmed by experimental studies under the same boundary conditions. However, it is not always possible to conduct experiments. Numerical analysis results can be validated with experimental analysis data which from has been obtained literature or with mesh independency analysis. Mesh independency research in numerical analysis increases the reliability of the analysis results [26]. This study has been investigated for $109 \mathrm{k}, 143 \mathrm{k}$ and $173 \mathrm{k}$ element number to show mesh independency. For these values, ammonia formation has been compared depend on time as shown Figure 5. The results are very close to each other in different element number at a temperature of $663 \mathrm{~K}$. Therefore, the analysis is independent of the mesh structure.

\section{Results and Discussion}

In this study, three different exhaust temperature values were studied numerically. SCR urea-water evaporation, thermolysis and hydrolysis reactions have been investigated. The isocyanic acid (HNCO)

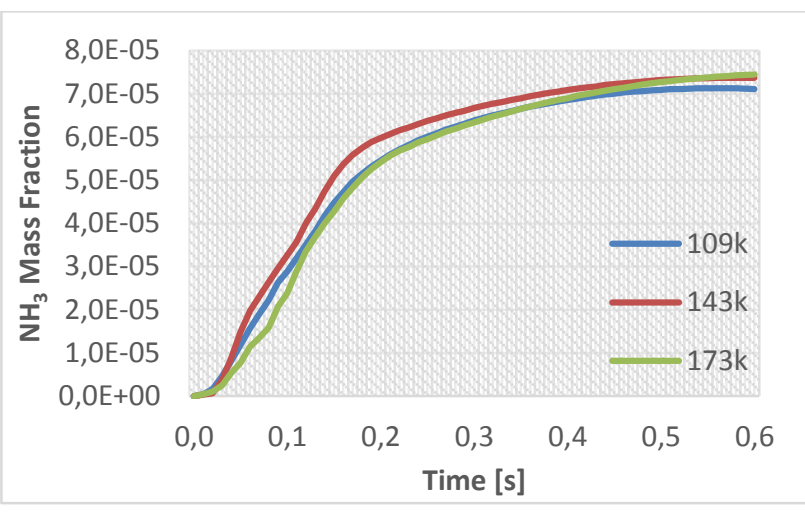

Figure 5. Mesh independency at $663 \mathrm{~K}$

and ammonia $\left(\mathrm{NH}_{3}\right)$ mass fractions formed by reaction with urea-water components sprayed from the nozzle has been determined by time. In the SCR system, the basic parameter of ammonia formation up to the catalyst input is temperature and velocity variables. The exhaust gas temperature allows water to evaporate from the UWS sprayed at $300 \mathrm{~K}$. Exhaust gas velocity affects the rate of reaction formation. The higher the speed, the lower the efficiency of the reactions before the catalyst. Temperature distribution for final equilibrium condition along the pipe is shown in Figure 6. The temperature distributions in SCR systems change the urea that are sprayed into the system and chemical reactions. The SCR system designed

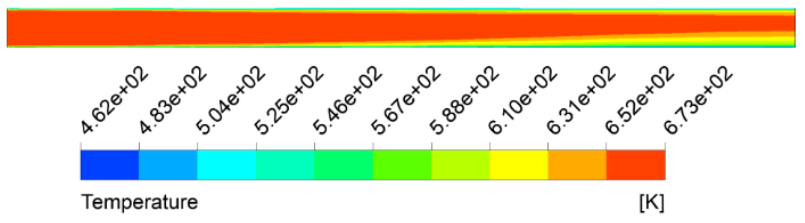

Figure 6. Temperature distribution

for the exhaust part of the diesel engine has been analysed for three different exhaust temperature values. Figure 7 below shows the time-dependent variation of the average temperature in the pipe for the exhaust temperature $663 \mathrm{~K}, 673 \mathrm{~K}$ and $683 \mathrm{~K}$. Pipe outlet temperature value is one of the important parameters in carrying out $\mathrm{NO}_{\mathrm{x}}$ reducing reactions in the catalyst. The $\mathrm{NO}_{\mathrm{x}}$ emission increases due to the high combustion temperature in the combustion chamber. This indicates that $\mathrm{NO}_{\mathrm{x}}$ emission is greatly affected by the cylinder gas temperature and the presence of oxygen during combustion. Therefore, both the value of the exhaust temperature at the SCR inlet and the value at the catalyst inlet are effective parameters for ammonia formation and $\mathrm{NO}_{\mathrm{x}}$ reduction. One of the most effective methods used to reduce $\mathrm{NO}_{\mathrm{X}}$ emissions used in diesel engines is the SCR system. 


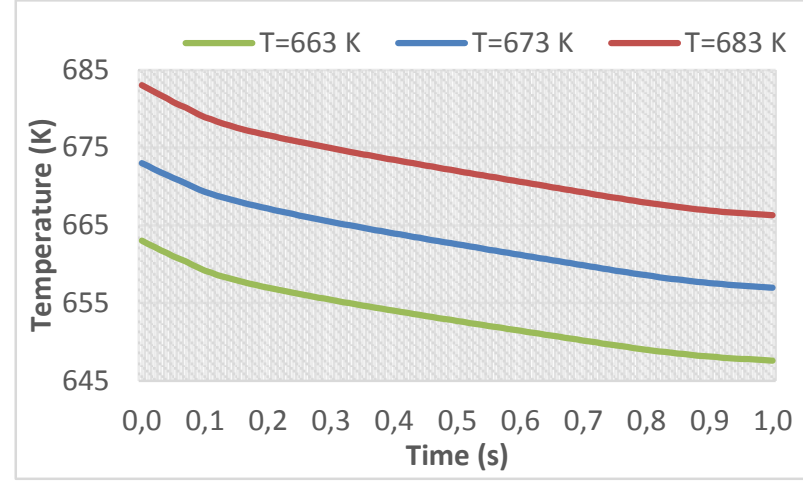

Figure 7. Average temperature in SCR pipe

Firstly, isocyanic acid solution which is sprayed with SCR system exhaust gas temperature effect evaporates to form solid or liquid isocyanic acid and water vapor. Urea injection time has been taken as $0.1 \mathrm{~s}$. In Figure 8 below, the species and their positions in the pipe have been determined for $0.7 \mathrm{~s}$ after the urea sputtering time. According to the results, the amount of urea has been first has converted to isocyanic acid and then to $\mathrm{CO}_{2}$ and ammonia. In this study, it has been assumed that diesel engine exhaust gas consists of air. Because temperature is the only effective parameter in ammonia formation between diesel engine output and SCR catalyst. UWS decomposition has been carried out by air intake at exhaust gas temperature. The figure shows the chemical components depend on exhaust gas velocity and pipe length. At the end of 0.7 seconds, it has been determined that the components such as ammonia, isocyanic acid and $\mathrm{CO}_{2}$ formed near the inlet of catalyst. Therefore, the length of the pre-catalyst pipe is an important variable in the formation of UWS in SCR systems. In SCR systems, the main chemical component used to reduce $\mathrm{NO}_{\mathrm{x}}$ emissions from the exhaust gas is $\mathrm{NH}_{3}$. The sprayed urea is converted to ammonia with temperature. The ammonia formation process for $0.8 \mathrm{~s}$ is illustrated in Figure 9 below. According to the results, ammonia formation has been initially formed around the injector during the spraying and has been shifted along the pipe over time. If the pipe length is not long enough, the efficiency of ammonia formation decreases. UWS decomposition pipe should be chosen in the most appropriate dimensions considering the exhaust gas velocity. if the pipe is less than this value, it will prevent the formation of enough ammonia and will have a negative effect on $\mathrm{NO}_{\mathrm{x}}$ reduction. In the sprayed urea pipe, first evaporation of the water, then thermolysis of urea, formation of isocyanic acid occurs. Isocyanic acid is a species formed between ammonia and urea. In the SCR pipe, urea is first converted into this species and then by hydrolysis this type into ammonia and water. Figure 10, 11

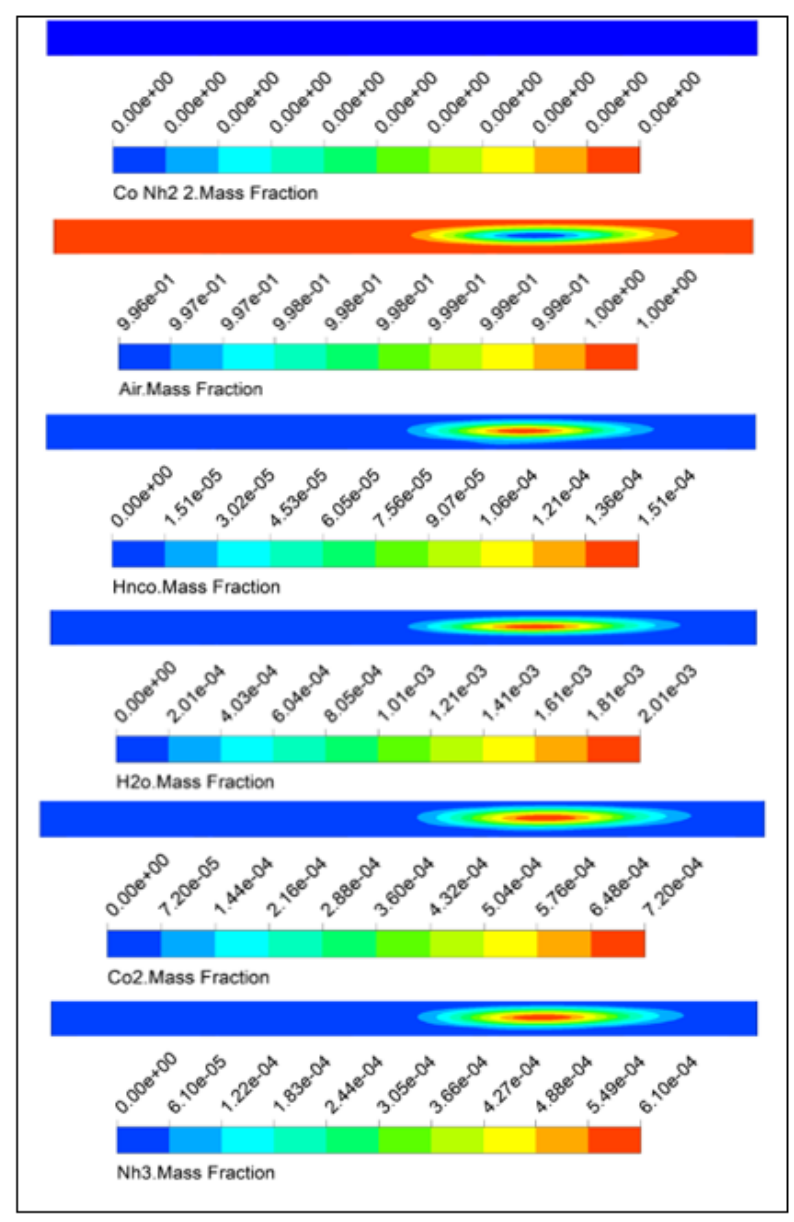

Figure 8. Chemical components at $0.7 \mathrm{~s}$

\begin{tabular}{|c|c|}
\hline Time & 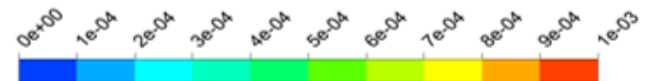 \\
\hline & $\mathrm{NH}_{3}$ Mass Fraction \\
\hline 0.1 & $\Rightarrow$ \\
\hline 0.2 & $=$ \\
\hline 0.3 & $=$ \\
\hline 0.4 & $=$ \\
\hline 0.5 & $\longrightarrow$ \\
\hline 0.6 & 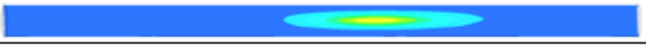 \\
\hline 0.7 & 2 \\
\hline 0.8 & $\longrightarrow$ \\
\hline
\end{tabular}

Figure 9. Ammonia formation over time

and 12 below show the mass fraction of isocyanic acid and ammonia in the SCR pipe depending on time. The Figures refer to the chemical components occurring at 663, 773 and $683 \mathrm{~K}$ exhaust temperature values, respectively. In this study, the effect of three different exhaust temperature parameters on ammonia formation in the SCR pipe has been investigated. In the results of the analysis, it has been determined that the amount of $\mathrm{NH}_{3}$ produced increases as the exhaust gas temperature increased. Ammonia formation gradients are given on the cross-section $\mathrm{x}=3.6 \mathrm{~m}$ for three different temperature values as illustrated in Figure 13. Analysis refers to the situation at the specified site 


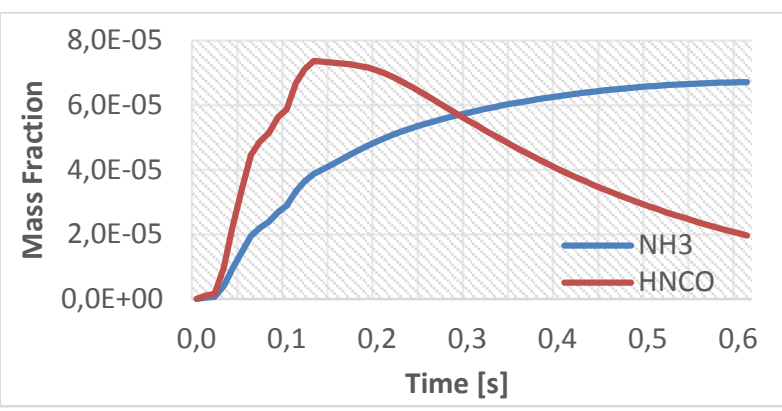

Figure 10. Formation of $\mathrm{NH}_{3}$ and $\mathrm{HNCO}$ at $663 \mathrm{~K}$

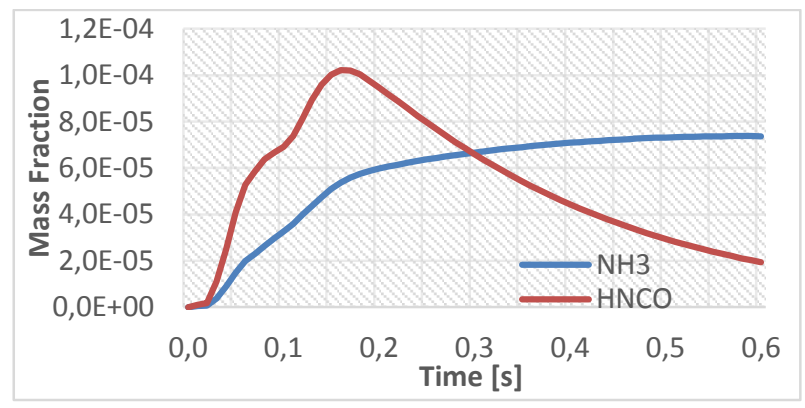

Figure 11. Formation of $\mathrm{NH}_{3}$ and $\mathrm{HNCO}$ at $673 \mathrm{~K}$

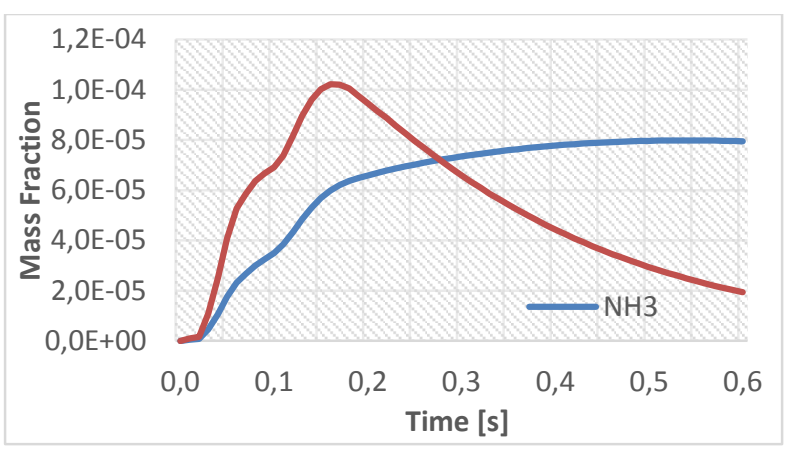

Figure 12. Formation of $\mathrm{NH}_{3}$ and $\mathrm{HNCO}$ at $683 \mathrm{~K}$

0.6 seconds after the start of injection. Ammonia formation has been observed near the centre of the pipe. The main reason for this is that there is not much velocity difference between the exhaust velocity and the injection velocity. Figure 14 below shows the ammonia formation process with depend on time for different temperature values. According to the figure, the formation of $\mathrm{NH}_{3}$ with the start of injection is minimal. Over time, the amount of ammonia in the pipe increases with the effect of temperature. It has been determined that the highest ammonia conversion has been $410 \mathrm{~K}$ and this efficiency decreased with temperature decrease.

\section{Conclusion}

In this study, the effect of exhaust gas temperature on the formation of SCR ammonia has been investigated numerically. In the UWS decomposition analysis, the exhaust gas output and

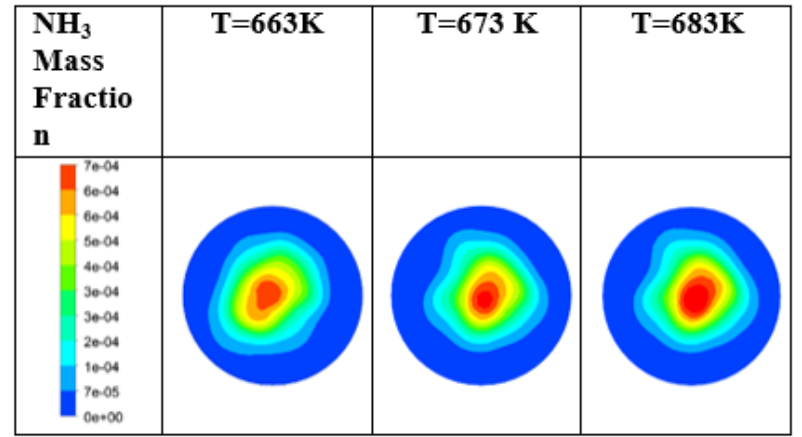

Figure 13. NH3 mass fraction at $0.6[s]$

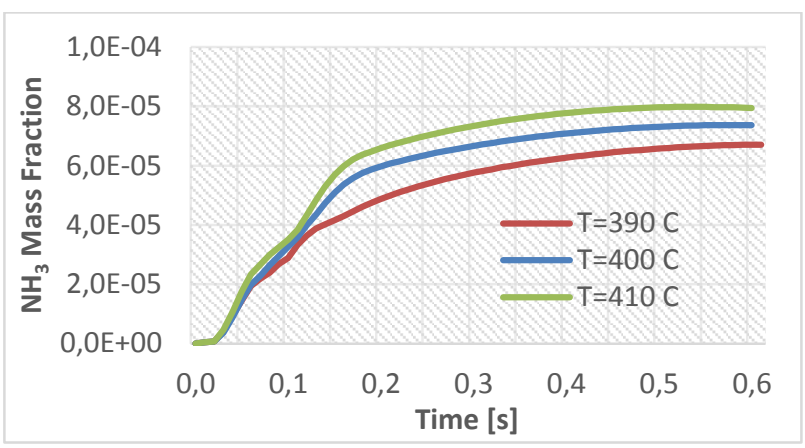

Figure 14. NH3 mass fraction at different exhaust temperature

the catalyst inlet have been examined. In this study, chemical species occurring along the pipe and their mass ratios have been determined. Ammonia formation efficiency has been compared at different exhaust temperature values under the same boundary conditions. the highest ammonia formation occurred at $410 \mathrm{C}$ exhaust temperature. Evaporation, thermolysis and hydrolysis reactions of urea solution in SCR has been investigated. water vapor $\left(\mathrm{H}_{2} \mathrm{O}\right)$, exhaust air, isocyanic acid (HNCO) and ammonia $\left(\mathrm{NH}_{3}\right)$ formation were determined by time along the pipe.

\section{References}

[1] Tian X. 'Study on mixing, modelling and control of an SCR system'. Doctor of Philosophy, Strathclyd (2016).

[2] Guo Y, Deng Y, Zhang J, Shen Y, Wilson C. 'Experimental and numerical analysis of NOx reduction in marine urea-SCR system'. International Conference on Information, Cybernetics, and Computational Social Systems, (2017) 450-5. 10.1109/ICCSS.2017.8091457.

[3] Kilpinen P. 'Optimization of a simplified submodel for NO emission prediction by CFD in large 4-stroke marine diesel engines'. Fuel Processing Technology, 91(2) (2010) 218-28. 10.1016/J.FUPROC.2009.10.001.

[4] Tan L, Feng P, Yang S, Guo Y, Liu S, Li Z. 'CFD studies on effects of SCR mixers on the performance of urea conversion and mixing of the reducing agent'. Chemical Engineering and 
Processing: Process Intensification, 123 (2018) 828. 10.1016/J.CEP.2017.11.003.

[5] Sadashiva Prabhu S, Nayak NS, Kapilan N, Hindasageri V. 'An experimental and numerical study on effects of exhaust gas temperature and flow rate on deposit formation in Urea-Selective Catalytic Reduction (SCR) system of modern automobiles'. Applied Thermal Engineering, 111 (2017) $1211-31$. 10.1016/J.APPLTHERMALENG.2016.09.134.

[6] Um HS, Kim D, Kim KH. 'Numerical study on the design of urea decomposition chamber in LP SCR system'. International Journal of Naval Architecture and Ocean Engineering, (2018). 10.1016/J.IJNAOE.2018.06.005.

[7] Capetillo A, Ibarra F. 'Multiphase injector modelling for automotive SCR systems: A full factorial design of experiment and optimization'. Computers \& Mathematics with Applications, 74(1) (2017) 188-200. 10.1016/J.CAMWA.2017.01.025.

[8] Ström H, Lundström A, Andersson B. 'Choice of urea-spray models in CFD simulations of urea-SCR systems'. Chemical Engineering Journal, 150(1) (2009) 69-82. 10.1016/J.CEJ.2008.12.003.

[9] Shen B, Li Z, Li J, Kong X, He L, Song J, et al. 'Development of a 1D Urea-SCR system model coupling with wall film decomposition mechanism based on engine bench test data'. Energy Procedia, 142 (2017) 3492-7. 10.1016/J.EGYPRO.2017.12.235.

[10] Kim JY, Ryu SH, Ha JS. 'Numerical Prediction on the Characteristics of Spray-Induced Mixing and Thermal Decomposition of Urea Solution in SCR System'. Fall Technical Conference of the ASME Internal Combustion Engine Division, (2004) 16570. 10.1115/icef2004-0889.

[11] Birkhold F, Meingast U, Wassermann P, Deutschmann O. 'Analysis of the Injection of UreaWater-Solution for Automotive SCR DeNOxSystems: Modeling of Two-Phase Flow and Spray/Wall-Interaction'. SAE International, (2006). 10.4271/2006-01-0643.

[12] Birkhold F, Meingast U, Wassermann P, Deutschmann O. 'Modeling and simulation of the injection of urea-water-solution for automotive SCR DeNOx-systems'. Applied Catalysis B: Environmental, 70(1-4) (2007) 119-27. 10.1016/J.APCATB.2005.12.035.

[13] Park K, Hong C-H, Oh S, Moon S. 'Numerical Prediction on the Influence of Mixer on the Performance of Urea-SCR System'. International Journal of Mechanical, Aerospace, Industrial, Mechatronic and Manufacturing Engineering, 8(5) (2014) 998-1004.

[14] Millo F, Rafigh M, Fino D, Miceli P. 'Application of a global kinetic model on an SCR coated on Filter (SCR-F) catalyst for automotive applications'. Fuel, 198 (2017) 183-92. 10.1016/J.FUEL.2016.11.082.

[15] Nguyen TDB, Lim Y-I, Eom W-H, Kim S-J, Yoo K-S. 'Experiment and CFD simulation of hybrid SNCR-SCR using urea solution in a pilot-scale reactor'. Computers \& Chemical Engineering, 34(10) (2010) 1580-9. 10.1016/J.COMPCHEMENG.2009.12.012.

[16] Nguyen TDB, Kang TH, Lim Y Il, Eom WH, Kim SJ, Yoo KS. 'Application of urea-based SNCR to a municipal incinerator: On-site test and CFD simulation'. Chemical Engineering Journal, 152(1) (2009) 36-43. 10.1016/j.cej.2009.03.025.

[17] Bayramoğlu K, Yilmaz S, Kaya KD. 'Numerical and Theoretical Thermal Analysis of Ship Provision Refrigeration System'. Journal of ETA Maritime Science, 7(2) (2019) 137-49. DOI ID: 10.5505/jems.2019.30922.

[18] Baleta J, Vujanović M, Pachler K. 'Numerical modeling of urea water based selective catalytic reduction for mitigation of NOx from transport sector'. Journal of Cleaner Production, 88 (2015) 280-8. 10.1016/J.JCLEPRO.2014.06.042.

[19] Baleta J, Martinjak M, Vujanović M, Pachler K, Wang J, Duić N. 'Numerical analysis of ammonia homogenization for selective catalytic reduction application'. Journal of Environmental Management, $203 \quad$ (2017) 1047-61. 10.1016/J.JENVMAN.2017.04.103.

[20] Nishad K, Ries F, Janicka J, Sadiki A. 'Analysis of spray dynamics of urea-water-solution jets in a SCR-DeNOx system: An LES based study'. International Journal of Heat and Fluid Flow, 70 (2018)

247-58. 10.1016/J.IJHEATFLUIDFLOW.2018.02.017.

[21] Choi C, Sung Y, Choi GM, Kim DJ. 'Numerical analysis of NOx reduction for compact design in marine urea-SCR system'. International Journal of Naval Architecture and Ocean Engineering, 7(6) (2015) 1020-34. 10.1515/IJNAOE-2015-0071.

[22] Wu B, Tang G, Chen X, Zhou CQ, Colella CP, Okosun T. 'Optimization of an urea decomposition chamber using CFD and VR'. Applied Thermal Engineering, 70(1) (2014) 827-37. 10.1016/J.APPLTHERMALENG.2014.05.044.

[23] ANSYS. 'ANSYS Fluent Theory Guide'. ANSYS 162 Documentation, 15317(July) (2015) 80. 10.1016/0140-3664(87)90311-2.

[24] Xu Y, Zhang Y, Liu F, Shi W, Yuan J. 'CFD analysis on the catalyst layer breakage failure of an SCR-DeNOx system for a $350 \mathrm{MW}$ coal-fired power plant'. Computers \& Chemical Engineering, 69 (2014) 119-27. 10.1016/J.COMPCHEMENG.2014.07.012.

[25] Birkhold F, Meingast U, Wassermann P, Deutschmann O. 'Modeling and simulation of the injection of urea-water-solution for automotive SCR DeNOx-systems'. Applied Catalysis B: Environmental, 70(1-4) (2007) 119-27. 10.1016/J.APCATB.2005.12.035.

[26] Bayramoğlu K. MSc Thesis. 'HAD (Hesaplamalı Akışkanlar Dinamiği) Yöntemiyle Gemi Dizel Motorlarinda Yanma Analizi'. 2018. 